\title{
DESAIN MULTIMEDIA INTERAKTIF PENGENALAN PERANGKAT KERAS PERSONAL KOMPUTER
}

\author{
Mariana Purba \\ Program Studi Manajemen Informatika, PoliteknikAnika, Sumatera-Selatan \\ Email: riagalihprasojo@gmail.com ${ }^{l)}$ \\ Corresponding author phone: +622380832450
}

\begin{abstract}
Abstrak
Perkembangan teknologi membawa dampak terhadap proses pembelajaran pada dunia pendidikan beberapa aplikasi yang dapat dijadikan sebagai media pembelajaran seperti ELearning, Zoom, Google Classroom dan lain sebagainya, dengan kondisi pandemic covid-19 mengharuskan peserta didik untuk dapat mengikuti pembelajaran tanpa harus bertatap muka dengan tenaga pengajar hal ini dilakukan dengan memanfaatkan akses jaringan namun terdapat beberapa permasalahan yang terjadi seperti buruknya konektivitas jaringan sehingga membuat peserta didik tidak dapat mengikuti proses pembelajaran dengan baik, hal ini membuat tenaga pengajar harus mampu berinovasi agar materi pembelajaran yang akan disampaikan dapat diberikan dengan baikuntukmencapai tujuan pembelajaran. Perancangan multimedia interaktif sebagai sarana pembelajaran yang diberikan kepada peserta didik sebagai media pembelajaran serta dapat diakses tanpa harus memiliki kuota internet. Metodologi yang dipergunakan untuk perancangan multimedia menggunakan pendekatan MDLC (Multimedia Development Life Cycle) dengan hasil penelitian berupa aplikasi multimedia yang dipergunakan untuk proses pembelajaran pengenalan perangkat keras pada personal komputer hal ini dirasakan sangat baik oleh peserta didik untuk menumbuhkan motivasi belajar dan memperdalam ilmu pengetahuan terkait dengan materi pembelajaran yang diberikan dengan tercapainya kompetensi inti melaluimultimedia interaktif.
\end{abstract}

Kata kunci: Multimedia, Pembelajaran, Interaktif, Perangkat keras.

\begin{abstract}
The development of technology has an impact on the learning process in the world of education some applications that can be used as learning media such as ELearning, Zoom, Google Classroom, and so on, with the pandemic covid-19 condition requires students to be able to follow the learning without having to face-to-face with teachers this is done by utilizing network access but some problems occur such as poor network connectivity so that students can not follow the learning process properly, this makes teachers must be able to innovate so that the learning materials that will be delivered can be given well to achieve learning objectives. Interactive multimedia design is a learning tool given to learners as learning and can be accessed withouthaving to have an internet quota. The methodology usedfor a multimedia design using MDLC (Multimedia Development Life Cycle) approach with research results in the form of multimedia applications used for the learning process of hardware introduction on personal computers is felt very well by learners to foster learning motivation and deepen knowledge related to learning materials provided by achieving core competencies through interactive multimedia.
\end{abstract}

Keywords: Multimedia, Learning, Interactive, Hardware.

\section{PENDAHULUAN}

Perkembangan teknologi yang semakin baik diiringi pertumbuhan pengetahuan dan kemampuan yang dimiliki oleh sumber daya manusia, dengan ilmu pengetahuan berdampak kepada pemecahan permasalahan yang semakin baik, dalam dunia pendidikan teknologi sudah dimanfaatkan untuk melakukan proses pembelajaran terlebih pada kondisi pandemic covid-19 yang mengharuskan proses pembelajaran dilakukan secara daring tanpa adanya pertemuan tatap muka di dalam kelas [1]. Oleh sebab itu, tenaga pendidik harus memiliki inovasi dalam memanfaatkan beberapa media pembelajaran sebagai penunjang agar proses pembelajaran dapat berjalan dengan baik serta peserta didik mampu memiliki pengetahuan dan kemampuan sesuai dengan kompetensi yang dimiliki dalam mengikuti proses pembelajaran [2], beberapa media yang telah dimanfaatkan seperti aplikasi eLearning, zoom, Google classroom dan sebagainya. Namun pada proses pembelajaran yang memanfaatkan media hanya dapat memberikan materi dan 
pertemuan melalui aplikasi dengan membutuhkan jaringan untuk dapat terhubung mengikuti proses pembelajaran [3].

Salah satu permasalahan yang terjadi peserta didik sering mengalami tidak dapat membuka media pembelajaran dikarenakan paket kuota internet yang terbatas dengan akses jaringan yang dirasakan sulit untuk dapat terhubung karena kualitas sinyal yang kurang stabil [4], untuk mendukung semangat peserta didik dalam proses pembelajaran dirasa perlu adanya inovasi media pembelajaran seperti media interaktif yang dapat menumbuhkan semangat peserta didik dalam belajar tanpa harus memerlukan jaringan internet dan kuota yang cukup besar [5], salah satu media yang dapat dimanfaatkan yaitu multimedia sebagai sarana pembelajaran interaktif yang berbasis flash [6]. Kelebihan media interaktif yakni dapat terinstal di aplikasi smartphone tanpa harus terkoneksi jaringan internet [7]. Perancangan multimedia interaktif dengan menggunakan adobe flash terdapat unsur menggabungkan multimedia seperti video, animasi, gambar, suara, dan sebagainya, multimedia pembelajaran interaktif merupakan komponen sistem penyampaian pengajaran yang mendukung proses pembelajaran yang dapat menarik minat perhatian peserta didik [8]. Proses pembelajaran dengan menggunakan platform smartphone mempermudah dalam mengakses konten belajar [9].

Salah satu pokok bahasan dalam pelajaran perakitan komputer yang dapat dirancang dengan multimedia interaktif dengan topik pembahasan pengenalan perangkat keras personal komputer. Mata pelajaran Perakitan Komputer khususnya materi pengenalan perangkat keras, peserta didik membutuhkan sebuah media pembelajaran yang menarik dan berdaya guna (efektif) [10], untuk memudahkan menghafal dan pengingat serta memahami fungsi komponen perangkat keras komputer berupa input, output, proses dan penyimpanan. Media pembelajaran interaktif berisi tentang materi perangkat komputer dilengkapi dengan latihan yang menunjang proses pembelajaran.

\section{DASAR TEORI}

\subsection{Multimedia}

Multimedia tidak hanya memiliki makna antara teks dan grafik sederhana saja akan tetapi dilengkapi dengan suara, gambar, animasi maupun teks dalam menjelaskan isi pada dashboard dengan pemanfaatan media komputer maupun smartphone [11]. Dengan pembelajaran yang berbasis teknologi multimedia dapat menumbuhkan semangat belajar serta dapat menciptakan hubungan dua arah, multimedia mengacu pada teknologi yang memadukan kemampuan berbagai media [12]

\subsection{Karakteristik Media Pembelajaran}

Media karakteristik media pembelajaran interaktif adalah curriculum, desain pembelajaran harus sesuai dengan kurikulum pendidikan yang sudah ditetapkan.[13] Aspek desain kurikulum dan pembelajaran terdiri dari 6 penilaian yaitu kesesuaian sasaran, kelengkapan unsur pembelajaran, kejelasan tujuan, konsistensi. tujuan-materi-evaluasi, pemberian contoh dan aspekaspek pedagogik. Content, penilaian content pada media interaktif didasarkan beberapa aspek, yakni kebenaran substansi materi, kecukupan cakupan, kedalaman, aktualitas, kelengkapan sumber [14]. Communication, aspek kejelasan pesan, menumbuhkan motivasi computer capacity, kemampuan komputer multimedia, creativity, tidak melanggar etika dapat diterima secara umum, dan mudah digunakan, tampilan desain yang menarik dan interactivity [15]

\section{METODOLOGI PENELITIAN}

Metodologi penelitian perancangan multimedia interaktif pengenalan perangkat komputer menggunakan pendekatan MDLC (Multimedia Development Life Cycle) dengan tahapan seperti concept, design, material collecting, assembly, testing dan distribution terlihat diagram pengembangan seperti pada gambar 1 .

1. Tahap concept (konsep) pada tahapan ini peneliti merumuskan sebuah tujuan perancangan aplikasi multimedia interaktif dalam pengenalan perangkat keras personal komputer dengan harapan peserta didik dapat mengetahui secara detail perangkat keras yang terdapat pada personal komputer dengan adanya multimedia yang terdiri dari unsur video, audio, teks, 
gambar dan animasi akan memberikan petunjuk yang menarik bagi peserta didik dalam mengikuti proses pembelajaran.

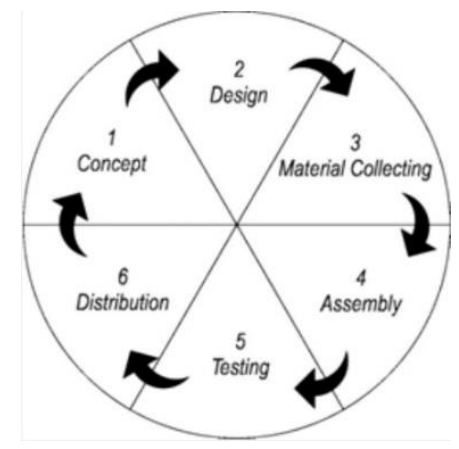

Gambar 1. Diagram Multimedia Development Life Cycle

2. Tahap Design (perancangan) pada tahap ini didesain sebuah spesifikasi secara rinci dalam multimedia interaktif yang akan di bangun dengan melihat kebutuhan pengguna serta menentukan beberapa halaman dashboard, flowchart dan struktur navigasi pada multimedia interaktif agar menjadi menarik perhatian peserta didik.

3. Tahap Material Collecting pada tahap ini peneliti melakukan pengumpulan bahan baku yang akan dipergunakan proses perakitan dashboard multimedia beberapa hal yang harus dipersiapkan seperti beberapa clipart image, animasi, audio, gambar, grafik foto dan sebagainya.

4. Tahap assembly (pembuatan) merupakan tahap dimana seluruh perancangan multimedia interaktif dilakukan diawali dengan proses pembuatan aplikasi berdasarkan story board, flowchart view, struktur navigasi, atau diagram objek yang berasal dari tahap design. Contohnya pada pembuatan presentasi, pembuatan dilakukan dengan memasukkan data yang digunakan untuk berbagai tampilan, serta menentukan screen dengan urutannya.

5. Tahapan Testing dilakukan untuk melakukan pengujian pada multimedia apakah sudah dapat berjalan sesuai dengan perancangan yang dilakukan untuk mencapai sebuah tujuan. Beberapa sistem mempunyai fitur yang dapat memberikan informasi bila terjadi kesalahan pada program. Suatu hal yang tidak kurang penting adalah aplikasi harus dapat berjalan dengan baik saat dipergunakan oleh peserta didik.

6. Tahap Distribution adalah langkah terakhir yang dilakukan dalam perancangan multimedia dengan pendekatan multimedia development life cycle, pada tahap distribusi multimedia diberikan kepada seluruh peserta didik yang mengikuti proses pembelajaran dalam pengenalan perangkat keras personal komputer dengan dilakukan evaluasi untuk mendapatkan respon dari peserta didik untuk proses pengembangan multimedia yang lebih lanjut di kemudian hari.

\section{PENGUJIAN DAN PEMBAHASAN}

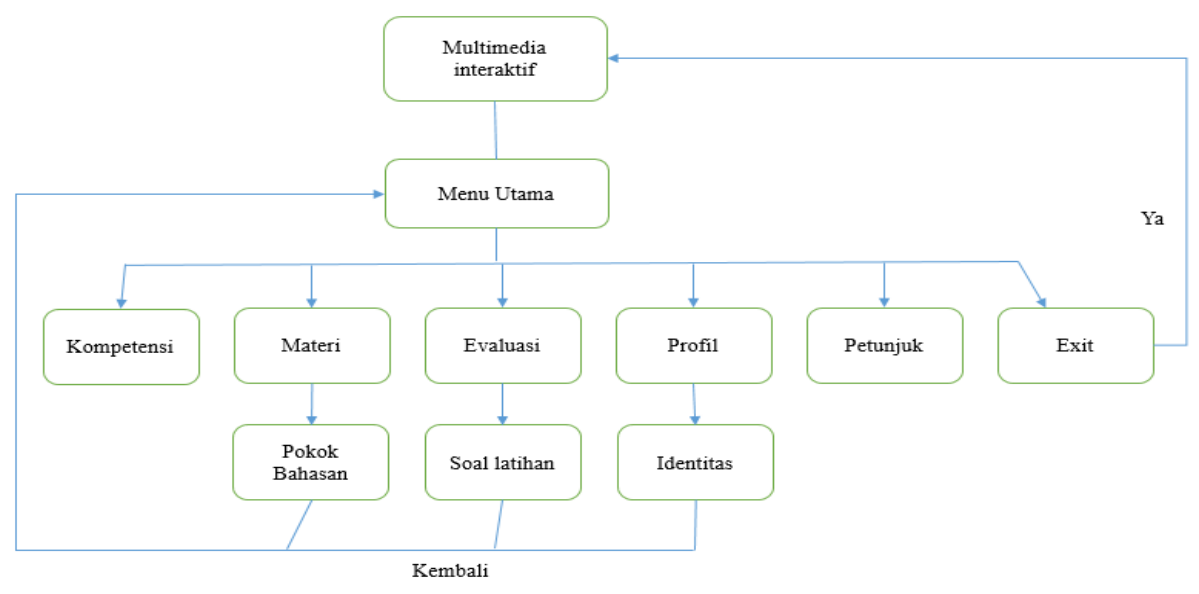

Gambar 2. Struktur Hirarki Menu Aplikasi Multimedia 
Hasil dari perancangan multimedia pengenalan perangkat keras personal komputer untuk meningkatkan motivasi peserta didik dalam proses pembelajaran pada masa pandemic covid-19 terdapat gambaran flowchart yang akan menjadi panduan peserta didik dalam menggunakan multimedia interaktif pengenalan perangkat keras personal komputer terlihat seperti gambar 2 . Terdapat beberapa menu navigasi pada multimedia interaktif yang dapat dipergunakan dalam proses pembelajaran.

Pembahasan dari perancangan multimedia pengenalan perangkat keras personal komputer dengan menggunakan bantuan software adobe flash cs6 memungkinkan multimedia dapat berjalan di desktop maupun perangkat smartphone adapun beberapa tampilan hasil dari perancangan sebagai berikut :

\section{Storyboard halaman utama}

Perancangan halaman utama peserta didik saat membuka multimedia interaktif pengenalan perangkat keras personal komputer maka akan tampil seperti gambar 3.

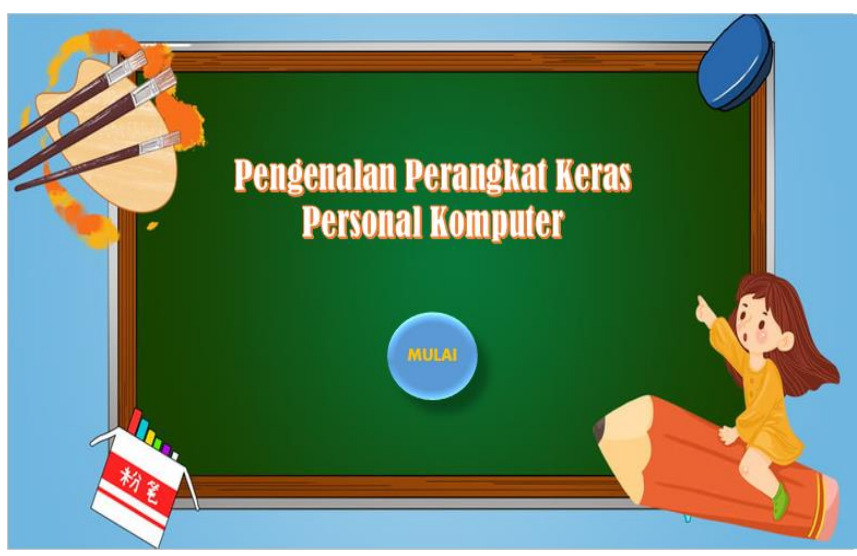

Gambar 3. Storyboard Halaman Utama

Peserta didik dapat melanjutkan mengakses multimedia interaktif dengan melakukan pilihan pada tombol mulai, sehingga peserta didik dapat mengakses menu utama.

\section{Story Menu Utama}

Menu utama berisi beberapa sub navigasi yang terdapat pada multimedia interaktif beberapa komponen yang terdapat pada menu utama diantaranya kompetensi, materi, evaluasi, profil, petunjuk dan exit seperti pada gambar 4.

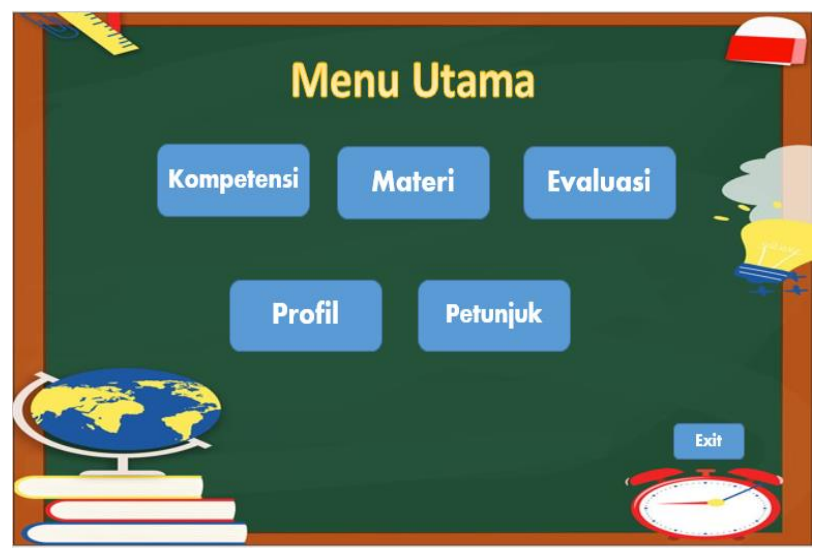

Gambar 4. Story Menu Utama

Pada menu utama peserta didik harus mengetahui fungsi dan isi dari menu yang terdapat pada dashboard.

1. Kompetensi berisikan pengetahuan yang harus dicapai oleh peserta didik yang terdiri dari kompetensi inti dan kompetensi dasar. 
2. Materi berisikan struktur kumpulan bahan pembelajaran yang sudah tersusun secara sistematis dalam proses pengenalan perangkat keras dengan menggunakan multimedia interaktif.

3. Evaluasi berisikan tahapan untuk melakukan pengukuran pengetahuan peserta didik yang terdiri dari beberapa soal test yang telah didesain untuk mengukur pengetahuan dan keterampilan peserta didik.

4. Profil berisikan identitas pengembang multimedia interaktif pengenalan perangkat keras pada personal komputer

5. Petunjuk berisikan struktur pengguna multimedia interaktif sehingga peserta didik dapat menggunakan aplikasi dengan mudah.

6. Exit berfungsi untuk mengakhiri proses menggunakan multimedia interaktif.

\section{Story Halaman Materi}

Halaman materi pembelajaran pada pengenalan perangkat keras personal komputer seperti gambar 10 terdapat beberapa bagian bahasan pada halaman materi yang terdiri dari Motherboard, Soundcard, Ram, Prosesor, Mouse, Keyboard, Hard disk, Disk Drive, VGA Card dan Monitor.

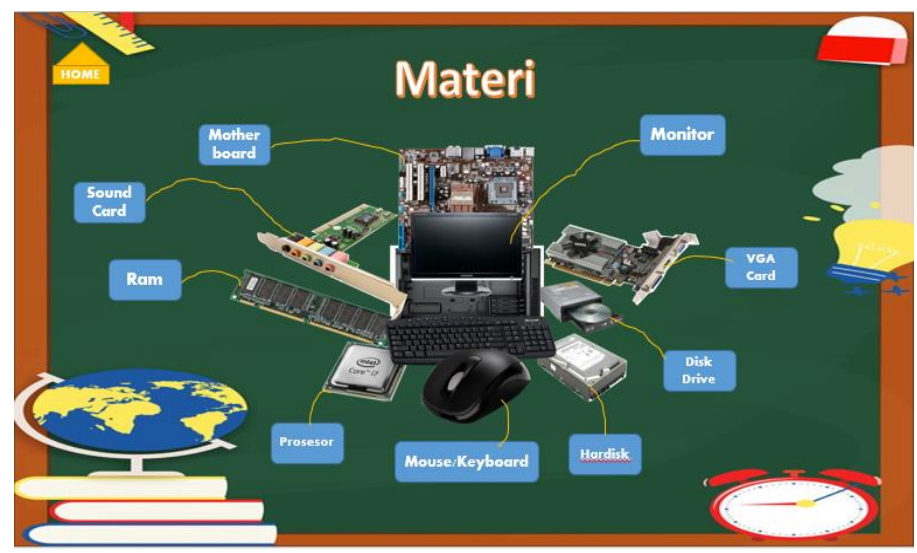

Gambar 10. Materi Perangkat keras personal komputer

Dengan penyajian tampilan pada materi seperti gambar 10 membuat peserta didik dapat dengan langsung mengetahui nama dan bentuk dari perangkat keras yang akan dibahas, hal ini berdampak kepada semangat peseta didik untuk terus mengikuti proses pembelajaran dan memperdalam materi sehingga capaian pembelajaran dapat tercapai dengan baik.

Hasil dari pengujian yang dilakukan oleh para ahli dan peserta didik terhadap multimedia interaktif dengan melihat beberapa penilaian hasil dari pengujian multimedia interaktif beberapa aspek seperti tampilan, pemrograman, aspek isi/materi dan aspek pembelajaran.

Tabel 1. Aspek Penilaian

\begin{tabular}{|c|l|c|c|}
\hline No & \multicolumn{1}{|c|}{ Aspek Penilaian } & Rata - Rata & Kategori \\
\hline 1 & Aspek Tampilan & 38 & Baik \\
\hline 2 & Aspek Pemrograman & 27 & Baik \\
\hline 3 & Aspek Isi/Materi & 22 & Baik \\
\hline 4 & Aspek Pembelajaran & 24 & Baik \\
\hline \multicolumn{2}{|c|}{ Jumlah } & 111 & Baik \\
\hline \multicolumn{2}{|c|}{ Rata -rata } & 3,83 & Baik \\
\hline
\end{tabular}

Berdasarkan tabel 1 multimedia interaktif layak untuk dipergunakan hal ini terlihat dari hasil pengujian berdasarkan pendapat ahli dan peserta didik dengan aspek tampilan baik sangat mudah dipergunakan, aspek pemrograman masuk kategori baik tidak ada kesalahan coding pemrograman, aspek materi sesuai dengan isi dari pencapaian kompetensi dasar dan inti, dan aspek pembelajaran pada kategori baik. 


\section{KESIMPULAN}

Multimedia interaktif pengenalan perangkat keras personal komputer dirasakan sangat membantu para peserta didik untuk memperdalam ilmu pengetahuan dengan inovasi pembelajaran yang menarik beberapa kesimpulan dari hasil perancangan multimedia sebagai berikut :

1. Multimedia dapat berjalan sesuai dengan perancangan.

2. Multimedia dapat membantu proses pembelajaran perangkat keras personal komputer

3. Multimedia sangat mudah digunakan oleh peserta didik

4. Peserta didik merasa sangat terbantu dan semangat dalam mengikuti proses pembelajaran

5. Peserta didik selalu bersemangat mengikuti pembelajaran dengan menggunakan multimedia interaktif.

\section{Daftar Pustaka}

[1] F. Armansyah, Sulton, and Sulthoni, "Multimedia Interaktif Sebagai Media Visualisasi Dasar-Dasar Animasi," J. Kaji. Teknol. endidikan, vol. 2, no. 3, pp. 224-229, 2019.

[2] G. Ngurah, S. Nugraha, I. M. Tegeh, and I. K. Sudarma, "Pengembangan Multimedia INteraktif Matematika Berorientasi Kearifan Lokal Kelas 3 Sekolah dasar negeri 1 Paket Agung," J. Edutech, vol. 7, no. 1, pp. 12-22, 2019.

[3] M. Istiqlal, "Pengembangan Multimedia Interaktif Dalam Pembelajaran Matematika," $J$. Ilm. Pendidik. Mat., vol. 2, no. ISSN 2502-8391, 2019.

[4] T. A. Dewi, "Implementasi Multimedia Interaktif Dalam Pembelajaran Ekonomi di Sekolah," J. Pendidik. Ekon., vol. 3, no. 2, pp. 1-10, 2015.

[5] I. bagus KT.trinawindu, A. kumala Dewi, and E. tri Narulita, "Multimedia Interaktif Untuk Proses Pembelajaran," Prabangkara, vol. 19, no. 1412-0380, pp. 35-42, 2016.

[6] D. Priyanto, "Pengembangan Multimedia Pembelajaran Berbasis Komputer," J. Pemikir. Altern. kependidikan, vol. 14, no. 1, pp. 1-13, 2009.

[7] Zulhemi, Adlim, and Mahidin, "Pengaruh Media Pembelajaran Interaktif Terhadap Peningkatan Keterampilan Berpikir Kritis Siswa," J. Pendidik. Sains Indones., vol. 05, no. 01, pp. 72-80, 2017.

[8] A. Fatoni and P. D. Kuraesin, "Rancang Bangun Multimedia Pembelajaran Interaktif Mata Pelajaran Ipa Terpadu Untuk Siswa Smpn 5 Kota Serang,” J. Sist. Inf., vol. 2, no. 24067768, pp. 47-50, 2015.

[9] A. Setiawan, T. Setiyaningsih, and T. Triwibowo, "Perancangan Mobile Application Berbasis Android Untuk Menunjang Kemampuan Kognitif Dan Psikomotorik Siswa Paud,"Netw. Eng. Res. Oper., vol. 4, no. 1, pp. 37-45, 2018, doi: 10.21107/nero.v4i1.110.

[10] W. Kurniawati, K. Ismatulloh, and Y. N. Kholisho, "Pengembangan Media Pembelajaran Berbasis Multimedia Interaktif Pada Mata Pelajaran Simulasi Digital Kelas x TKJ,” J. Pendidik. Inform., vol. 2, no. 2, pp. 74-83, 2018.

[11] I. Diah and S. Nita, "Media Pembelajaran Berbasis Multimedia Interaktif untuk Meningkatkan Pemahaman Konsep Mahasiswa," J. Comput. Inf. technlogy, vol. 1, no. 2, pp. 68-75, 2018.

[12] Zarkasi and A. Taufik, "Implementasi Pembelajaran Fikih berbasis Multimedia Interaktif Macro-Enabled untuk meningkatkan keaktifan siswa," J. Pendidik. Agama Islam, vol. 7, no. 2, 2019.

[13] L. Marlisa and S. Purnama, "Pengembangan Multimedia Interaktif Pengenalan Salat Untuk Meningkatkan Aspek Perkembangan Anak Usia Dini," J. Penelit., vol. 12, no. 1, pp. 403-426, 2018.

[14] Nopriyanti and P. Sudira, "Pengembangan Multimedia Pembelajaran Interaktif Kompetensi dasar Pemasangan Sistem Penerangan dan Wiring Kelistrikan Di SMK," J. Pendidik. Vokaso, vol. 5, no. 1, 2015.

[15] A. K. Tarigan, S. D. Nasution, and A. Karim, "Aplikasi Pembelajaran Citra Dengan Menggunakan Metode Computer Assisted Instruction ( Cai )," vol. 3, no. 4, pp. 1-4, 2016. 